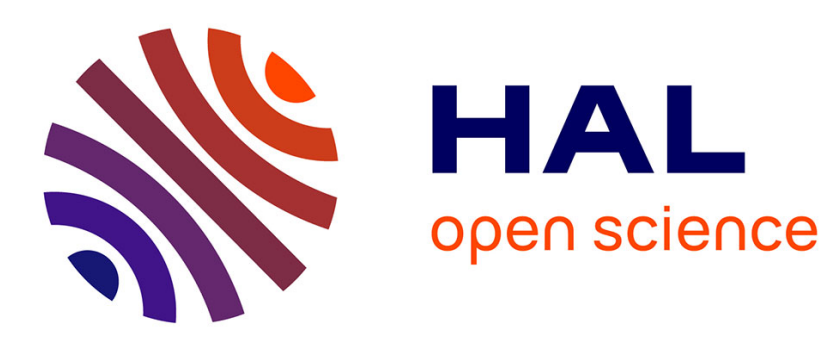

\title{
Electrical properties of interlevel deposited oxides related to polysilicon preparation
}

\author{
C. Cobianu, O. Popa, D. Dascalu
}

\section{To cite this version:}

C. Cobianu, O. Popa, D. Dascalu. Electrical properties of interlevel deposited oxides related to polysilicon preparation. Journal de Physique IV Proceedings, 1993, 03 (C3), pp.C3-467-C3-473. 10.1051/jp4:1993365 . jpa-00251422

\section{HAL Id: jpa-00251422 https://hal.science/jpa-00251422}

Submitted on 1 Jan 1993

HAL is a multi-disciplinary open access archive for the deposit and dissemination of scientific research documents, whether they are published or not. The documents may come from teaching and research institutions in France or abroad, or from public or private research centers.
L'archive ouverte pluridisciplinaire HAL, est destinée au dépôt et à la diffusion de documents scientifiques de niveau recherche, publiés ou non, émanant des établissements d'enseignement et de recherche français ou étrangers, des laboratoires publics ou privés. 


\title{
Electrical properties of interlevel deposited oxides related to polysilicon preparation
}

\author{
C. COBIANU, O. POPA and D. DASCALU \\ Center of Microtechnology, P.O. Box 38-160, Bucharest 72225, Romania
}

\begin{abstract}
Few papers investigated the electrical properties of interlevel high temperature oxides low pressure chemically vapour deposited (LPCVD HTO) $\mathrm{SiO}_{2}$. Silicon dioxide obtained by the surface reaction between $\mathrm{SiH}_{2} \mathrm{Cl}_{2}$ and $\mathrm{N}_{2} \mathrm{O}$ at $900^{\circ} \mathrm{C}$ on LPCVD polysilicon shows lower electrical conductivity in comparison to $\mathrm{SiO}_{2}$ thermally grown on polysilicon. It was demonstrated a FowlerNordheim mechanism for the electrical conduction through the $\mathrm{LPCVD} \mathrm{HTO} \mathrm{SiO}_{2}$ interpoly dielectrics (2). This paper studies the effect of deposition temperature (in the range of $530^{\circ} \mathrm{C}-613^{\circ} \mathrm{C}$ ) of LPCVD silicon on the electrical properties of interlevel HTO LPCVD $\mathrm{SiO}_{2}$ films deposited on phosphorus doped layers. Phosphorous drive-in from $\mathrm{POCl}_{3}$ was performed in $\mathrm{N}_{2}$ ambient in order to avoid any interface roughness due to thermal oxidation. The low field electrical conduction through these HTO layers can be about one order of magnitude decreased by reducing the deposition temperature of polysilicon from 560 to $530^{\circ} \mathrm{C}$ while the currents from high fields are not essentially reduced. These results are explained in terms of surface roughness decrease as a function of lowering of deposition temperature. The breakdown fields of $\mathrm{LPCVD} \mathrm{HTO} \mathrm{SiO}_{2}$ layers, in the range of 8-10 MV/cm, prove the high quality of the dielectric. It is demonstrated that the dielectric breakdown phenomenon originates in the bulk of LPCVD HTO $\mathrm{SiO}_{2}$ films .
\end{abstract}

Based on this experimental study, an improved technology of interlevel structures for polysilicon floating gate EEPROM devices can be proposed. 


\section{Introduction}

Few papers (1-3) investigated the electrical properties of high temperature oxides low pressure chemically vapor deposited (LPCVD HTO $\mathrm{SiO}_{2}$ ) on polysilicon. These deposited oxides show lower electrical conductivity with respect to $\mathrm{SiO}_{2}$ thermally grown on polysilicon. This paper presents the effect of deposition temperature of LPCVD silicon on the electrical properties of these interlevel deposited dielectrics. Electric conduction through LPCVD HTO $\mathrm{SiO}_{2}$ at low and high electric fields and dielectric breakdown of these HTO layers as a function of preparation conditions of LPCVD silicon thin film are studied. Based on these results, we propose an improved technology of interlevel structures for floating gate EEPROM devices, consisting of LPCVD of smooth surface silicon and HTO layer.

\section{Experimental}

The LPCVD silicon layers $(0.4 \mu \mathrm{m}$ in thickness) were directly deposited on $n+$ monocrystalline silicon by thermal decomposition of silane at three temperatures as follows : $530^{\circ} \mathrm{C}, 560^{\circ} \mathrm{C}$ and $613^{\circ} \mathrm{C}$. The thickness of LPCVD silicon layers was measured by profilometric method (with an $\alpha$-step Tencor Instrument) on separate substrates (consisting of a thermal $\mathrm{SiO}_{2}$ layer of thickness of $150 \mathrm{~nm}$ grown on monocrystalline silicon) in order to avoid possible errors of reflectometric methods due to the changes of optical properties of amorphous LPCVD silicon. The deposited silicon layers were phosphorous doped ( fromPOCl${ }_{3}$ liquid source). The $\mathrm{P}$ drive-in was performed in dry $\mathrm{N}_{2}$ at $1000^{\circ} \mathrm{C}$ for $30 \mathrm{~min}$. LPCVD HTO $\mathrm{SiO}_{2}$ films (about $65 \mathrm{~nm}$ in thickness) , obtained by the surface reaction between $\mathrm{SiH}_{2} \mathrm{Cl}_{2}$ and $\mathrm{N}_{2} \mathrm{O}$ at $900^{\circ} \mathrm{C}$ were deposited onto these polysilicon layers. MOS capacitors (an area of $4 \mathrm{x}$ $10^{-4} \mathrm{~cm}^{2}$ ) were delineated by photolithography, after $\mathrm{Al}$ film deposition by e-gun evaporation. Then a standard sintering treatment in forming gas at $450^{\circ} \mathrm{C}$ was finally applied.

The electrical measurements were performed by a data acquisition system consisting of a Keithley model 616 picoammeter, programmable voltmeter and power supply controlled by HP 9845 computer. The d.c. electric conduction through these interlevel structures was measured by applying each d.c. voltage for about $1 \mathrm{~min}$ before each current reading. The dielectric breakdown of these LPCVD $\mathrm{HTO} \mathrm{SiO}_{2}$ layers was measured by recording the voltage on the capacitor at a current of $1 \mu \mathrm{A}$ and checking then at a low electric field $(1 \mathrm{MV} / \mathrm{cm})$ that a destructive phenomenon had alreay occured before. The above electrical measurements were carried out with a negative bias, both on substrate and aluminium in order to see the electrode effects on these electrical phenomena. The experimental results presented in this paper as mean values were averaged over 150 events on each wafer.

\section{Results}

By the above experimental set-up we have studied the electrical conduction through interlevel LPCVDHTO $\mathrm{SiO}_{2}$ films at low electric fields (the current density at $3 \mathrm{MV} / \mathrm{cm}$ was mapped on each wafer), at high electric field (over $6 \mathrm{MV} / \mathrm{cm}$ ) and the dielectric breakdown, with electron injection from both 
electrodes. According to Table I, the mean value of current density at $3 \mathrm{MV} / \mathrm{cm}$ injected from polysilicon increases by one order of magnitude (from $0.3 \times 10^{-8} \mathrm{~A} / \mathrm{cm}^{2}$ to $3 \times 10^{-8} \mathrm{~A} / \mathrm{cm}^{2}$ ) when the deposition temperature of LPCVD silicon increases from $530^{\circ} \mathrm{C}$ to $613^{\circ} \mathrm{C}$ with an unexpected increase of current range for the temperature increase from $530^{\circ} \mathrm{C}$ to $560^{\circ} \mathrm{C}$.

Table I. Mean current density ( $\mathrm{J}$ at $3 \mathrm{MV} / \mathrm{cm})$, breakdown field $\left(\mathrm{E}_{\mathrm{bf}}\right)$ and apparent barrier height ( $\phi_{\text {app }}$ ) related to deposition temperature of LPCVD silicon layer.

\begin{tabular}{|c|c|c|c|c|c|c|}
\hline $\mathrm{T}_{\mathrm{d}}$ & \multicolumn{2}{|c|}{$\mathrm{e}^{-}$injection from polysilicon } & \multicolumn{2}{|c|}{$\mathrm{e}^{-}$injection from Aluminium } \\
\hline of polysilicon & $\begin{array}{c}\mathrm{J} \\
\mathrm{A} / \mathrm{cm}^{2}\end{array}$ & $\begin{array}{c}\mathrm{E}_{\mathrm{hf}} \\
\mathrm{MV} / \mathrm{cm}\end{array}$ & $\begin{array}{c}\Phi_{\mathrm{aDD}} \\
\mathrm{eV}\end{array}$ & $\begin{array}{c}\mathrm{J} \\
\mathrm{A} / \mathrm{cm}^{2}\end{array}$ & $\begin{array}{c}\mathrm{E}_{\mathrm{bf}} \\
\mathrm{MV} / \mathrm{cm}\end{array}$ & $\begin{array}{c}\Phi_{\mathrm{aDv}} \\
\mathrm{eV}\end{array}$ \\
\hline $530^{\circ} \mathrm{C}$ & $0.310^{-8}$ & 8.7 & 2.23 & $0.710^{-9}$ & 9.7 & 1.29 \\
\hline $560^{\circ} \mathrm{C}$ & $2.510^{-8}$ & 8.9 & 0.43 & $1.010^{-9}$ & 10.0 & 1.24 \\
\hline $613^{\circ} \mathrm{C}$ & $3.010^{-8}$ & 9.1 & 0.37 & $1.410^{-9}$ & 10.1 & -- \\
\hline
\end{tabular}

When the electron injection is from aluminium (this electrode is negatively biased ) the current densities through the interlevel LPCVD HTO $\mathrm{SiO}_{2}$ layers ( at constant low electric field, of $3 \mathrm{MV} / \mathrm{cm}$ ) are much lower ( from $0.7 \times 10^{-9} \mathrm{~A} / \mathrm{cm}^{2}$ to $1.4 \times 10^{-9} \mathrm{~A} / \mathrm{cm}^{2}$ ) and they present a slight dependence on the technology of polysilicon preparation but with the same trend as before, i.e., an increase of current with the increase of deposition temperature of LPCVD silicon layer.

According to Fig. 1 , at high electric fields (over $7.5 \mathrm{MV} / \mathrm{cm}$ ) the current density through LPCVD $\mathrm{HTO} \mathrm{SiO}_{2}$ layers, injected from polysilicon increases with deposition temperature of LPCVD silicon layer. Thus, for an applied electric field of $7.6 \mathrm{MV} / \mathrm{cm}$, the current density through LPCVD HTO $\mathrm{SiO}_{2}$ interlevel dielectric layers are $4.6 \times 10^{-6} \mathrm{~A} / \mathrm{cm}^{2}, 6 \times 10^{-6} \mathrm{~A} / \mathrm{cm}^{2}$ and $1.6 \times 10^{-5} \mathrm{~A} / \mathrm{cm}^{2}$ corresponding to an increase of deposition temperature of LPCVD silicon layer from $530^{\circ} \mathrm{C}$ to $613^{\circ} \mathrm{C}$, respectively. The above results show that the interlevel structure with silicon layer deposited at $530^{\circ} \mathrm{C}$ can also withstand to high currents through interlevel dielectrics required for erasing cycle of EEPROM devices (4).

At high electric fields ( $7.5 \mathrm{MV} / \mathrm{cm}$ ), a similar result is obtained when the electrons are injected from $\mathrm{Al}$ electrode with a current density through interlevel dielectrics from about $3.2 \times 10^{-7} \mathrm{~A} / \mathrm{cm}^{2}$ to $6 \times 10^{-}$ $7 \mathrm{~A} / \mathrm{cm}^{2}$ and $1.4 \times 10^{-6} \mathrm{~A} / \mathrm{cm}^{2}$. This corresponds to the increase of deposition temperature of LPCVD silicon layer from $530^{\circ} \mathrm{C}$ to $560^{\circ} \mathrm{C}$ and $613^{\circ} \mathrm{C}$, respectively . In fact , if the applied electric field is increased over the above value, the current densities through interlevel dielectrics for the interlevel structures with LPCVD silicon prepared at $530^{\circ} \mathrm{C}$ and $560^{\circ} \mathrm{C}$ are practically the same, for electron injection from $\mathrm{Al}$ electrode. 


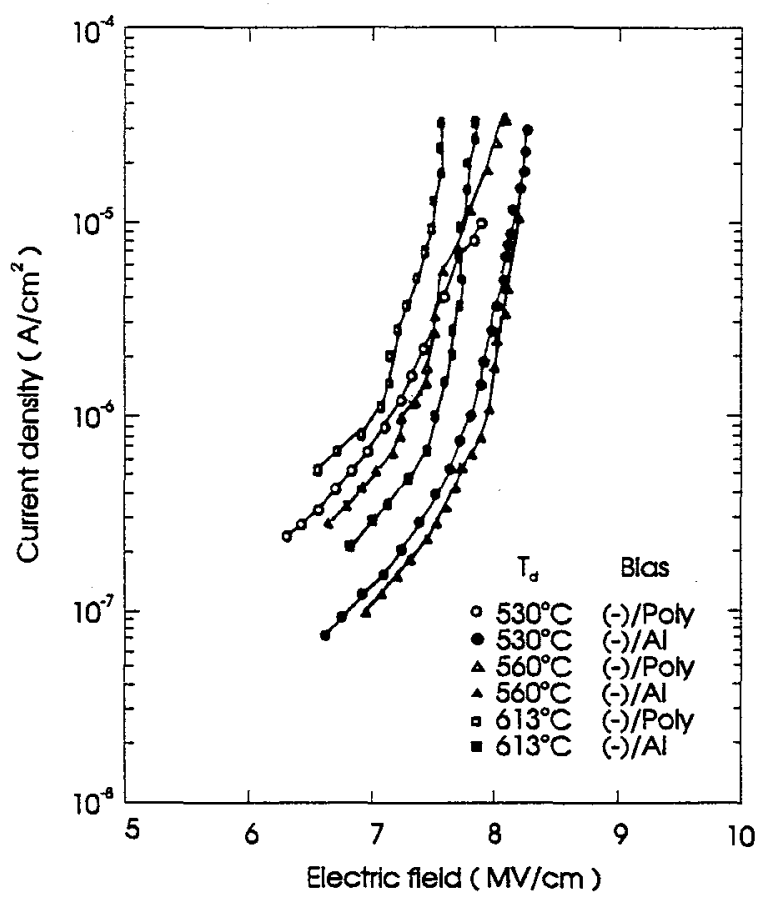

Fig.1 Current density vs. high electric field through interlevel LPCVD $\mathrm{HTO} \mathrm{SiO}_{2}$ layers as a function of deposition temperature of LPCVD silicon $\left(T_{d}\right)$ and electrodes biasing.

According to Table I, contradicting the expectations, the mean values of LPCVD HTO $\mathrm{SiO}_{2}$ dielectric breakdown fields present a very slow increase as a function of deposition temperature of LPCVD silicon. The dielectric breakdown fields increase from $8.7 \mathrm{MV} / \mathrm{cm}$ to $8.9 \mathrm{MV} / \mathrm{cm}$ and to 9.1 $\mathrm{MV} / \mathrm{cm}$ when the deposition temperature of LPCVD silicon increases from $530^{\circ} \mathrm{C}$ to $560^{\circ} \mathrm{C}$ and to $613^{\circ} \mathrm{C}$, respectively, for a negative biasing of polysilicon layer. When the $\mathrm{Al}$ electrode is negatively biased, the dielectric breakdown fields are about $1 \mathrm{MV} / \mathrm{cm}$ higher with respect to the above values (9.7 MV/cm, $10 \mathrm{MV} / \mathrm{cm}$ and $10.1 \mathrm{MV} / \mathrm{cm}$ ).

\section{Discussion}

The roughness of polysilicon - thermal polyoxide interface increases the electrical conductivity of interpolysilicon structures by electric field enhancement on the asperities of polysilicon surface Thus, it decreases the charge retention in floating gate EEPROM devices $(4,5)$

As the thermal oxidation of polysilicon induces an additional interface roughness (6), (especially at low oxidation temperatures where the process is mainly controlled by the reaction with the substrate) determined by the different crystalline orientations, we have proposed recently $(2,3)$, an improved 
technology of interpolysilicon structure preparation. It is based on smooth surface LPCVD

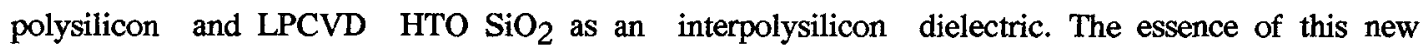
technology consists in combining the smooth surface LPCVD polysilicon with the LPCVD HTO $\mathrm{SiO}_{2}$ technology and the elimination (as much as possible) of any thermal oxidation of the surface of polysilicon. It was demonstrated that, at high electric fields, the current density through these LPCVD HTO $\mathrm{SiO}_{2}$ interlevel structures follows a Fowler-Nordheim mechanism, specific to high quality thermal oxides (2).

Within this paper, we further perform a a systematic investigation of the role of deposition temperature of LPCVD silicon, where that temperature was decreased to the about the chemical lower limit of thermal decomposition of silane on the electrical characteristics of deposited LPCVD HTO $\mathrm{SiO}_{2}$. In fact , the deposition rate of LPCVD silicon at $530^{\circ} \mathrm{C}$ was about $0.7 \mathrm{~nm} / \mathrm{min}$.

From the above experimental results, we observe that the electrical conduction through these deposited interlevel dielectrics is still sensitive to the interface morphology. The observed decrease of electric current through LPCVD HTO $\mathrm{SiO}_{2}$ interlevel layers as a function of deposition temperature of LPCVD silicon layers can be explained in terms of surface roughness decrease.

In order to perform a more detailed demonstration of the above statement, we have calculated the apparent barrier heights between polysilicon and LPCVD HTO $\mathrm{SiO}_{2}$ (for electron injection from polysilicon to HTO ) from the slopes of the straight lines of the Fowler- Nordheim characteristics ( J/E 2 versus 1/E) coresponding to each J-E curve presented in Fig. 1, and also the apparent barrier heights between aluminium electrod and HTO (for electron injection from Al electrode). These barrier heights are presented in Table 1 for both interfaces. It has been clearly shown earlier (6) that a higher surface roughness of the interface corresponds to a lower apparent barrier height for electron tunneling through that interface. Therefore, in our case, we can demonstrate from data presented in Table I, that the surface smoothness can be highly improved by lowering the deposition temperature of LPCVD silicon from $560^{\circ} \mathrm{C}$ to $530^{\circ} \mathrm{C}$. Also, from the apparent barrier heights associated to Al-HTO interface , which are quite similar for interlevel structures with LPCVD silicon prepared at $530^{\circ} \mathrm{C}$ or $560^{\circ} \mathrm{C}$, we suggest that a certain level of planarization of the outer surface of $\mathrm{LPCVD} \mathrm{HTO} \mathrm{SiO}_{2}$ layer takes place during deposition. The very low value of the apparent barrier height corresponding to Al-HTO interface for LPCVD polysilicon prepared at $613^{\circ} \mathrm{C}$, in accordance with the corresponding one for the polysilicon-HTO can prove a reduced quality of interlevel structure with LPCVD polysilicon prepared at $613^{\circ} \mathrm{C}$.

From current measurements at constant low electric fields ( $J$ at $3 \mathrm{MV} / \mathrm{cm}$ ) with electron injection from polysilicon (Table I), where the current density decreases by about one order of magnitude as a result of lowering the silicon deposition temperature to $530^{\circ} \mathrm{C}$, we understand that the decrease of deposition temperature of LPCVD silicon from $560^{\circ} \mathrm{C}$ to $530^{\circ} \mathrm{C}$ can further improve the technology presented earlier $(2,3)$ This determines higher storage times in floating gate EEPROM devices (From 
the point of view of interlevel structure processing, we have seen that the above improvement of the electrical behaviour of the structure could be obtain if only the last $30 \mathrm{~nm}$ of LPCVD silicon were deposited at $530^{\circ} \mathrm{C}$ ). The slighter dependence of low field current density (with electron injection from Al electrode) through $\mathrm{HiO}$ as a function of LPCVD silicon deposition temperature may be also correlated with a smoother outer surface of HTO layer.

The unexpected dielectric breakdown results, where the breakdown fields of LPCVD $\mathrm{HTO} \mathrm{SiO}_{2}$ layers are not affected by interface roughness may indicate that this phenomenon is mainly determinated by weak points from the bulk of dielectric. The fact that the dielectric breakdown of LPCVD HTO SiO2 layer is higher by $1 \mathrm{MV} / \mathrm{cm}$ when the $\mathrm{Al}$ electrode is negatively biased might be connected to a lower level of current through capacitor structure .

\section{Conclusions}

This paper shows that the electrical conduction phenomena in interlevel structures with LPCVD HTO $\mathrm{SiO}_{2}$ films as a dielectric are dependent on the preparation conditions of LPCVD silicon.

By reducing the deposition temperature of LPCVD silicon from $560^{\circ} \mathrm{C}$ to $530^{\circ} \mathrm{C}$, we can further improve the technology of interlevel structures used in floating gate EEPROM devices, consisting in smooth surface LPCVD polysilicon, LPCVD HTO $\mathrm{SiO}_{2}$ interlevel layer and the elimination of thermal oxidation of polysilicon substrate.

The currents densities at low electric fields through interlevel LPCVD-HTO $\mathrm{SiO}_{2}$ layers (with electron injection from polysilicon) can be about one order of magnitude decreased by reducing the deposition temperature of LPCVD silicon from $560^{\circ} \mathrm{C}$ to $530^{\circ} \mathrm{C}$ while the currents from high fields are not essentially lowered.

The experimental results of electrical conduction through LPCVD $\mathrm{HTO} \mathrm{SiO}_{2}$ interlevel layers are explained in terms of surface roughness of LPCVD silicon. At high electric fields, the dependence of current density on the electric field has been interpreted in terms of Fowler-Nordheim mechanism , which provided a qualitative evidence of surface roughness decrease as the deposition temperature of LPCVD silicon decreases to the lower chemical limit of silane thermal decomposition (about $530^{\circ}$ C, where the deposition rate of LPCVD silicon was approximatelly $0.7 \mathrm{~nm} / \mathrm{min}$ ).

The breakdown fields of LPCVD HTO $\mathrm{SiO}_{2}$ films deposited on LPCVD silicon prepared at different temperature are in the range of $8-10 \mathrm{MV} / \mathrm{cm}$, which proves the high quality of this interlevel structure . Taking into account the very weak dependence of dielectric breakdown on preparation conditions of LPCVD silicon, we demonstrate that this phenomenon originates in the bulk of LPCVD HTO $\mathrm{SiO}_{2}$ films. 
Based on these results, we propose an improved technology of interlevel structures for floating gate EEPROM devices based on LPCVD polysilicon (deposited at 530 ${ }^{\circ} \mathrm{C}$ ) and LPCVD $\mathrm{HTO} \mathrm{SiO}_{2}$ interlevel dielectrics.

\section{References}

1. PEAK H.L. and VERNEY J.F., Electrochemical Society Meeting, San Francisco, 1983, May 8-13, paper 90.

2. COBIANU C. and POPA O., Electrochemical Society Meeting , Washington DC, 1991, May 5-10, paper 466.

3. COBIANU C., POPA O. and DASCALU D., IEEE Electron Devices Letters, to be published in May 1993 issue

4. Huff H.R. , HALVORSON R.D., CHU T.L. and GUTERMAN D., J. Electrochem. Soc., 127 (1980) 2482 .

5. HEIMAN P.A., MURARKA S.P. and SHENG T.T., J. Appl. Phys., 53 (1982) 6240.

6. FARAONE L. and HARBEKE G., J. Electrochem. Soc., 133 (1986) 1410. 